\title{
Systematically Addressing Inconsistencies in the Rural Social Disorganization and Crime Literature
}

\author{
Maria T. Kaylen \\ Doctoral Candidate \\ Department of Criminal Justice \\ Indiana University \\ 302 Sycamore Hall \\ Bloomington, Indiana USA 47405 \\ mkaylen@indiana.edu \\ William Alex Pridemore \\ Professor \\ Department of Criminal Justice \\ Indiana University \\ Room 313, Sycamore Hall \\ Bloomington, Indiana USA 47405 \\ wpridemo@indiana.edu
}

Contact author - Maria T. Kaylen: mkaylen@indiana.edu; 0108128559325

\begin{abstract}
The rural criminological literature has recently experienced an increased interest in structural theories of crime, with social disorganization theory being the primary emphasis. This article summarizes and synthesizes the existing literature that specifically tests social disorganization theory in rural communities, focusing on consistencies and inconsistencies in the findings as well as theoretical and methodological questions that have been raised. We then describe how we (the authors of this article) have taken steps to systematically address some of these questions. Finally, we offer suggestions for research advancements in this area.
\end{abstract}

Keywords: Social Disorganization Theory, Rural Communities, Crime Measurement 
Inconsistencies in the Rural Social Disorganization and Crime Literature - Kaylen and Pridemore

\section{Introduction}

The rural crime literature has recently been dominated by structural studies, with many focusing on social disorganization theory. These studies tend to utilize different data sources, measures of social disorganization, samples, and measures of dependent variables. Furthermore, they tend to have mixed results, though authors typically conclude social disorganization theory generalizes to rural areas. The goal of the current paper is to provide a review of the rural social disorganization research to date, including theoretical and methodological questions that have been raised, and how we (i.e., the authors of the current article) have begun to systematically address these questions.

Social disorganization theory was brought into the forefront of criminology by Shaw \& McKay's (1942) study of juvenile delinquency in Chicago neighborhoods and regained popularity with Sampson's work in this area (1985; Sampson \& Groves 1989). The general premise of the theory is that communities with high rates of poverty, residential instability, family disruption, and ethnic heterogeneity are poorly integrated and thus less able to exert informal social control, socialize youth, and solve shared problems. That is, these communities are said to be socially disorganized. As a result, these communities have higher rates of crime. The theory was developed to explain urban crime patterns and has been tested primarily in urban areas. However, recent theoretical and empirical work in this area has extended to rural communities.

\section{Findings from Prior Literature on Social Disorganization and Crime in Rural Communities}

Although the literature on rural crime in general is fairly small and the empirical literature on social disorganization and crime in rural areas even smaller, both topics seem to be gaining greater attention and the number of studies is growing. As is usual with nascent empirical literatures, the findings are mixed. Some consistent findings can be found related to certain aspects of social disorganization and crime in rural areas, while findings for other aspects are less consistent. We briefly summarize this literature here.

\section{Summary of Findings}

For the most part, from their tests of social disorganization theory in rural settings, scholars usually conclude that their findings support the theory. Scholars often find significant relationships between the structural antecedents of social disorganization poverty, residential instability, family disruption, and ethnic heterogeneity - and crime and thus conclude the theory generalizes to rural areas. In the first study of this kind, Petee and Kowalski (1993) found residential mobility, racial heterogeneity, and percent single parents to be positively associated with robbery and assault in rural counties. Barnett and Mencken (2002) found percent of nonwhite residents and population change to be positively related to violent crime in nonmetropolitan counties. Similarly, Lee, Maume, and Ousey (2003) found residential mobility and percent divorced to be positively associated with homicide in rural communities. Wells and Weisheit (2004) studied both rural and urban areas to see which 
urban indicators of crime are applicable to the rural setting. They used three categories of nonmetropolitan counties based on population size and size of communities. Included in their variables were the common structural indicators of social disorganization, though the authors operationalized their measures slightly differently than in other rural social disorganization studies. Their general pattern of findings was that population change, family instability, and racial diversity were positively and significantly associated with violent and property crime rates in nonmetropolitan counties. Their findings for their measure of economic resources were mixed. Bouffard and Muftić (2006) found ethnic diversity, female-headed households, and density to be associated with assaults in rural counties. Most recently, Li (2011) utilized data on all non-metropolitan counties in the United States (excluding those with populations less than 500 or that had too much missing crime data) to test the effects of the structural antecedents of social disorganization on a variety of property and violent crime rates. While $\mathrm{Li}$ followed the social disorganization approach, he used a combination of operationalizations of the independent variables that make it difficult to directly compare results with other studies. However, his general findings were that measures of family disruption, percent urban population, and the GINI coefficient (his measure of ethnic heterogeneity) were consistently and significantly related to crime rates ( $\mathrm{Li} \mathrm{2011).} \mathrm{Thus,} \mathrm{the} \mathrm{positive} \mathrm{association} \mathrm{of} \mathrm{rural}$ crime rates with residential instability, ethnic heterogeneity, and family disruption is largely consistent in the empirical literature on social disorganization in rural areas.

While patterns of similarity exist between the rural and urban social disorganization literature, and within the rural literature, researchers have found a number of differences in the relationships between the structural antecedents of social disorganization and violence in rural areas. Petee and Kowalski (1993), Osgood and Chambers (2000), Lee, Maume, and Ousey (2003), and Li (2011) found that percent low income, poverty, poverty concentration, and SES index, respectively, were not significantly associated with measures of violence in rural counties. Barnett and Mencken (2002), meanwhile, found resource disadvantage to be positively associated with violent crime and $\mathrm{Li}$ (2011) found his SES index to be positively associated with property crime rates. In contrast, Bouffard and Muftić (2006) found a strong negative association between poverty and assault, robbery, and rape. Unlike the rest of the rural literature, Lee, Maume, and Ousey (2003) found racial dissimilarity to be negatively associated with rural homicide rates. Meanwhile, Bouffard and Muftic (2006) found their diversity index was only significantly associated with assault when population density and proximity to urban areas were controlled. Together with the important methodological and theoretical questions that remain, and which we summarize below, these dissimilarities and inconsistent results call into question strong assertions that the theory generalizes to rural areas.

\section{The Osgood and Chambers Study}

The most widely known and cited study of social disorganization theory in rural areas is the Osgood and Chambers piece that was published in Criminology in 2000 (along with a companion piece Osgood [2000] published that details their use of the negative binomial estimator with aggregate data). The study sample was non-metropolitan counties in four 
states with youth arrests for violent crimes, obtained from the Uniform Crime Reports, as the dependent variables. Census measures of residential instability, ethnic heterogeneity, femaleheaded households (a measure of family disruption), poverty, unemployment, adjacency to metropolitan areas, and population at risk (a proxy for population density) were used as the independent variables. The authors conclude that social disorganization theory does generalize to non-metropolitan settings because they found significant effects of residential instability, ethnic heterogeneity, and female-headed households. The economic measures did not have significant effects but the authors propose the poverty finding is not surprising given that poverty is negatively correlated with residential instability, opposite the correlation in urban areas. Furthermore, there was not enough variability in their unemployment measure to expect to find a significant effect.

\section{Methodological Questions}

The mixed findings and varied data sources in the rural social disorganization theory literature naturally produce a number of methodological questions. First, the previous studies have tested only the direct effects of the social structural factors of disorganization on crime. The full systemic model suggests these structural factors - residential instability, family disruption, ethnic heterogeneity, and poverty-operate indirectly on crime through informal social control and community social disorganization (Kasarda \& Janowitz 1974; Kornhauser 1978; Sampson \& Groves 1989; Shaw \& McKay 1942). In other words, there are many reasons that poverty, residential instability, family disruption, and ethnic heterogeneity may be related to crime, and social disorganization is only one of those reasons. Without testing the full model, little can actually be concluded about the generalizability of the theory to rural communities. Questions remain about whether inconsistent findings of the effects of the structural antecedents of disorganization on crime are due to model misspecification or the theory not generalizing to rural areas.

Second, these studies have relied exclusively on official crime data. Measurement research, however, questions the validity of police data on crime in rural areas (Lott and Whitley 2003; Maltz \& Targonski 2002, 2003; Wiersema, Loftin, \& McDowall 2000). It may be that inconsistent theoretical findings are due to limitations of the crime data. Specifically, if crime reporting is associated with some of the structural antecedents of social disorganization or with an unmeasured aspect of social disorganization, estimates could be biased. For example, rural communities have small populations, and evidence reveals that such communities are more tightly knit and have a higher density of acquaintanceship (Freudenberg 1986) and closer social proximity (Weisheit, Falcone, \& Wells 2006). Given the close social proximity and the small populations, it may be that rural victims are not only more likely to know their offenders but less likely to report to the police so as not to upset the social order. Such a situation would bias coefficients in favor of an association between disorganization and crime, even though the reality is that cohesion can facilitate crime victim acquiescence and real rates of crime.

Third, Wells and Weisheit (2004) demonstrate that the definition of communities becomes important for these types of analyses. In their study, they divide counties into four 
categories: metropolitan, nonmetropolitan city (nonmetropolitan county with cities of 20,000 or more), nonmetropolitan town (nonmetropolitan county with cities between 2,500 and 20,000), and nonmetropolitan rural (nonmetropolitan county with no incorporated areas of 2,500 or more). Although some correlates of crime (e.g., family instability) are relatively stable across the four communities types, other correlates are not (e.g., economic resources). These findings suggest that the way communities are classified can have an effect on studies of social disorganization and crime. Thus, the methodological question of how to classify communities also becomes a theoretical question of why some nonmetropolitan communities operate differently with regard to social disorganization and crime.

\section{Theoretical Questions}

Osgood and Chambers (2000) and others (e.g., Bouffard and Muftić 2006; Lee, Maume, and Ousey 2003) raise an important theoretical question about social disorganization theory in rural areas. That is, they suggest that Shaw and McKay's (1942) postulation that poverty itself does not produce social disorganization but rather the association of poverty with other structural factors leads to disorganized communities. These relationships, however, may be different in rural and urban areas. Osgood and Chambers (2000) point out, for instance, the potential importance of including measures of economic heterogeneity in these rural models; while urban communities tend to be economically homogeneous, rural communities tend to be more economically diverse.

Another interesting point raised by a number of rural social disorganization authors regards the population size-crime relationship. Osgood and Chambers (2000), for instance, find that population size does not have an effect on crime after reaching about 4,000 juveniles per county. They offer three possible explanations for this finding. First, limited opportunities for offending exist in less densely populated areas. Second, and related to methodological questions about measurement, they suggest opportunities to detect and report offenses are sparse in less densely populated areas. Third, this population size-crime relationship is the result of adolescents in small communities committing crimes in larger communities (where their crimes are recorded). $\mathrm{Li}$ (2011) finds that population density is positively associated with murder and robbery rates, negatively associated with aggravated assault rates, and has no significant association with rates of various property crimes. The findings of Wells and Weisheit (2004), discussed in the section above, also raise questions about how community size affects the social disorganization-crime relationship.

\section{Our Three Studies of Social Disorganization and Crime in Rural Areas}

We have carried out three studies of social disorganization and crime in rural areas. The first was an initial study undertaken to extend the work of Osgood and Chambers (2000) by testing hypotheses about the potential conditioning effects of population size and density. This study resulted in unexpected findings that were, surprisingly to us, not supportive of the social disorganization model in rural areas. Our second study addressed the main potential methodological reasons for this discrepancy in findings. Our conclusion was that the inferences drawn about the association between social disorganization and crime in rural 
areas are sensitive to the measure of the dependent variable. Our third study took on the most important limitation in this literature: the failure to test the full social disorganization model in rural areas. To carry out this novel analysis, we drew on innovations from the classic Sampson and Groves (1989) study, since the urban literature on social disorganization and crime at the time faced the same three key limitations now faced by the rural literature: inconsistent results, reliance on official crime data, and the failure to test the full social disorganization model. Using the same data source and model estimation techniques as Sampson and Groves, but extracting out a rural sample, we tested the full social disorganization model for the first time in the rural literature. We again failed to find support for it.

\section{Initial Study and its Unexpected Results}

The most widely cited study of social disorganization and crime in rural areas is Osgood and Chambers (2000). Their results were supportive of the theory and they concluded that social disorganization's impact on violence is generalizable to rural communities. Given our interests in rural crime, and given the attention this study had received and the authors' careful documentation of data and method (also see Osgood 2000), in our initial study (Kaylen \& Pridemore 2011) we decided to extend the Osgood and Chambers study incrementally and to use the same measures for the independent variables, sample selection criteria, and methods.

Using data from rural Missouri counties, the original aim of our initial study was to determine if population size and density condition the effects of social disorganization on rural youth violence. Based on the work of Osgood and Chambers, we assumed the existence of an association between disorganization and youth violence in rural areas. Further, (1) the theory suggests that smaller communities may be more tightly knit than larger ones, (2) "rural" encompasses a broad range of community sizes, densities, and spatial location (e.g., closer or further away from metropolitan areas), (3) population size and density may differentially influence the nature of social relations in rural communities (Weisheit and Wells 1996), and (4) empirical evidence from the rural crime literature suggests variation in crime rates and a differential impact of social disorganization on crime across different rural community types (Bouffard \& Muftić 2006; Osgood \& Chambers 2000; Weisheit \& Wells 2005).

As it turned out, our assumption of an association between social disorganization and rural youth violence was premature. The results from our analysis of rural counties in Missouri revealed very little support for social disorganization theory. We found only one measure of social disorganization, single-parent households, to be associated with youth violent victimization, leading us to very different conclusions relative to Osgood and Chambers (2000). Almost as an afterthought at this stage due to our unexpected findings, we also found no support for the idea that population size or density conditioned the effect of social disorganization on youth violent victimization in our sample. 
At this stage, we proposed a number of methodological and theoretical explanations for the differences between the two studies. Three potential methodological explanations stood out. First was the possibility of the influence of spatial autocorrelation. We accounted for this in our analysis but Osgood and Chambers did not, so this might provide an explanation (though we thought the likelihood of this being the culprit was small). The second possibility was sample composition. While we purposely used the same sample selection criteria as Osgood and Chambers, they used nonmetropolitan counties from Florida, Georgia, South Carolina, and Nebraska, and we used nonmetropolitan counties from Missouri. The third possibility was the measurement of the dependent variable. This was our most substantial departure from the Osgood and Chambers study. Specifically, Osgood and Chambers used youth violent arrest rates from the UCR as their measure of the dependent variables. Subsequent to the publication of their study, however, a series of studies revealed serious measurement errors in county-level UCR arrest data, especially in counties with small populations (Lott \& Whitley 2003; Maltz \& Targonski 2002, 2003). In light of these findings, we employed hospital data on injuries due to assaults among youth and young adults as our measure of serious violent victimization. ${ }^{1}$

There are also potential theoretical explanations for the different conclusions drawn from these two studies. The association between social disorganization and crime may not generalize to rural areas, or any association between disorganization and crime may operate differently in rural relative to urban areas. The nature of social structure and its impact on social relations in rural communities may also be different than in urban communities. For example, the effects of the structural antecedents of social disorganization may be (nearly) completely moderated by high levels of community cohesion in rural areas, though this would require that levels of cohesion in rural communities (Freudenburg 1986; Weisheit et al. 2006; Weisheit \& Wells 1996) be much higher than in urban areas. The nature of social relations may also be different in rural relative to urban communities. For example, Donnermeyer (2006) notes that some forms of rural community organization may actually facilitate crime, providing evidence that some types of rural crime may not be reported by victims or police may not follow up complaints due to fear of disrupting community cohesion (Barclay, Donnermeyer, \& Jobes 2004; Donnermeyer \& Barclay 2005). Further, Donnermeyer (2006) and DeKeseredy, Schwartz, Fagin, and Hall (2006) suggest that community organization in rural areas can actually support violence against women, as men in these communities share stories and techniques of violence so that it becomes part of the mainstream culture in these areas. Finally, while the intervening variables of social disorganization may influence rural crime rates, the structural antecedents of disorganization commonly used in urban studies may not apply. Traditional measures like poverty, mobility, ethnic heterogeneity, and population density may not be the causes of rural disorganization. Perhaps the decline in small and local businesses - like drug, grocery, and hardware stores and the rise of big box stores, which can wreak havoc on local businesses and downtown areas, creates disruption in community ties. This is analogous to the impact of farm job loss in rural America during the 1980s, which had debilitating effects on community organization and crime rates. So, while rural communities are certainly subject to larger regional, national, 
and global influences, they must be understood in terms of their own social organization (Weisheit et al. 2006), which will not always mirror urban organizational patterns.

\section{Answering the Methodological Questions}

The findings from our first study led to very different conclusions about the impact of social disorganization and crime relative to Osgood and Chambers. Before addressing the theoretical implications this presents, however, it seemed appropriate to understand the role that data and method might have played in the differing conclusions. Although we had used the same sample selection criteria and the exact same measures of the explanatory variables as Osgood and Chambers (as described above), we still suggested three main potential methodological reasons for the conflicting results of the two studies: spatial autocorrelation, sample composition, and measurement of the dependent variable. It took considerable effort to systematically address these three issues. What follows below is a brief summary of the methods and results. The details are available in Kaylen (2010) and Kaylen and Pridemore (2013a). We note that access to the original data from the Osgood and Chambers study was necessary for several of the analyses that we describe here. These data were graciously provided to us by Wayne Osgood.

Spatial autocorrelation: While we tested for spatial autocorrelation in our Missouri models, Osgood and Chambers had not. Although we did not expect this to be the cause of our different findings, we wanted to be sure. Therefore, using Osgood and Chambers' data we carried out global and local tests for spatial autorcorrelation of the standardized residuals in their original models. We used ArcMap 9.3.1 (ESRI 2009) to undertake the spatial analyses separately for each state. For global tests we used a global Moran's I statistic (Moran 1950) with an inverse Euclidean distance spatial weights matrix. When the global tests revealed spatial autocorrelation was present, the global statistic was decomposed for the model using Anselin's local Moran's I statistic (Anselin 1995) with an inverse Euclidean distance spatial weights matrix. We created a series of dummy variables to account for significant local spatial autocorrelation among contiguous counties in each state. These dummy variables were systematically added to the models individually and in concert in order to see whether their presence changed the inferences drawn from the models. Our analyses revealed that spatial autocorrelation did not substantially impact the results presented by Osgood and Chambers, allowing us to conclude that that untested spatial autocorrelation in the Osgood and Chambers study did not account for differences in the social disorganization inferences drawn between their study and ours.

Sample composition: To address whether sample composition might be the source of the different conclusions drawn between the two studies, we compared the results of model estimation from the two different samples when the same measure of the dependent variable was employed. The reasoning for this is that consistent results for models using the same dependent and independent variables but different samples would rule out sample composition as the cause of differences between the original two studies. On the other hand, inconsistent results for models using the same dependent and independent variables but 
different samples would suggest sample composition might be a cause of differences between the original two studies.

In the first step we compared results from the Osgood and Chambers sample with our sample when hospital victimization data were used. The results from model estimation revealed consistent results across the two samples. Specifically, of the four main measures of the structural antecedents of social disorganization - poverty, residential instability, ethnic heterogeneity, and single-parent female-headed households - only the last was significant. As a side note, these findings were not supportive of social disorganization theory's generalizability to rural areas, but were consistent with the results from our initial study of Missouri (Kaylen \& Pridemore 2011). In other words, when hospital victimization data instead of UCR arrest data were used for the Osgood and Chambers sample, the results from their sample turned out to be the same as ours. The consistent results across the samples using violent victimization as the dependent variable is evidence that sample composition is not at fault.

In the second step, we carried out the same analyses again but used UCR arrest data for both samples. In contrast to the conclusions about the role of sample composition drawn above when using victimization data, comparison of the results of the arrest models between samples suggests sample composition may play a role in explaining the differences between the Osgood and Chambers and Kaylen and Pridemore studies. That is, there were substantial differences between the inferences drawn about the social disorganization variables between the two samples. Nevertheless, the documented measurement errors in county-level arrest data call into question the conflicting results of the sample composition tests. In other words, whether this conflict is due to sample composition (i.e., social disorganization operates differently in the two samples) or inconsistent measurement error in arrest data cannot be answered by only comparing the arrest models between samples. When the victimization and arrest between-sample findings are taken together, however, it suggests that differences in the conclusions drawn by Osgood and Chambers and Kaylen and Pridemore might be the result of measurement errors in arrest data.

Measurement of the dependent variable: To determine if the conflicting results of the two studies are due to differences in the measurement of the dependent variable, we compared results from the arrest and victimization models within each sample. Consistent results using the same sample (and independent variables) but different measures of the dependent variable would rule out dependent variable measurement as the source of differences. On the other hand, inconsistent results would suggest dependent variable measurement as a likely source of differences between the original two studies. To address these items, we created four data sets: (1) hospital victimization data for the Missouri sample, (2) aggravated assault arrest data for the Missouri sample, (3) hospital victimization data for the Florida, Georgia, Nebraska, and South Carolina sample, and (4) aggravated assault arrest data for the multi-state sample.

For the Missouri sample, the inferences drawn from the model employing arrest data were the same as those drawn from the model using victimization data. These results for 
victimization do not support social disorganization theory in rural areas. Only female-headed households and poverty are significantly associated with youth victimization, with the latter in the negative (unexpected) direction. The remaining social disorganization measures residential instability and ethnic heterogeneity - were not significantly associated with victimization. The aggravated assault model also did not support social disorganization theory in rural Missouri. None of the measures of social disorganization were significantly associated with aggravated assault arrests.

Looking at the Osgood and Chambers sample, on the other hand, when we compared the results for the victimization model to those for the arrest model it was clear that there were substantial differences in the inferences drawn in relation to social disorganization theory. Consistent with the results from the Missouri models, the results for the victimization model did not support social disorganization theory in this sample. Of the measures of social disorganization, only the female-headed households association is significant. In comparing these results to the aggravated assault arrest model for this sample, there were considerable differences in the inferences drawn about the applicability of social disorganization theory to rural areas. The arrest model largely supported social disorganization theory with residential instability, ethnic heterogeneity, and female-headed households positively and significantly associated with youth violence.

In short, based on the comparisons shown here we concluded that the different inferences drawn by Osgood and Chambers and Kaylen and Pridemore were very likely due to measurement of the dependent variable.

\section{The First Test of the Full Social Disorganization Model in Rural Areas}

The single most important limitation to both empirical tests of social disorganization theory in rural areas and the conclusions drawn from them is that the theory as presented has actually not been tested. As we described above, the main idea is that several social structural factors, often driven by forces external to the community, lead to a reduction in social cohesion within the community, thereby reducing its ability to control the behavior of its members. To this point, however, the lack of data on the intervening variables measuring social cohesion and collective efficacy at the community level have meant that scholars have only been able to look at associations between the structural antecedents of social disorganization and crime. This misspecified model in rural tests of social disorganization results in a failure to test the most important questions about social disorganization. First, do the negative structural antecedents influence social cohesion and organization in rural areas? Second, if so, does this more local and proximate level of cohesion covary with violence rates in rural communities? In other words, does the entire systemic model truly operate in rural areas in the same way it appears to operate in urban areas?

While we have outlined the inconsistent evidence for the direct effects of the structural antecedents of social disorganization on crime in rural areas from tests carried out thus far, there simply have been no tests of the full model. This is a major limitation to any conclusions drawn about the theory's efficacy. There are two smaller, but not unimportant, 
limitations to the rural social disorganization and crime literature thus far. One of these is that, with the exception of our study described above, studies to date have relied solely on official crime data to measure the dependent variables. As we outlined above, prior research presents serious questions about the validity of police data on crime in rural areas (Lott \& Whitley 2003; Maltz \& Targonski 2002, 2003; Wiersema, Loftin, \& McDowall 2000), and our study just described (Kaylen \& Pridemore 2013a) revealed the measurement of the dependent variable (i.e., violence) to be the source of the inconsistent results between the Osgood and Chambers study and our initial study. The other limitation is the inconsistent results stemming from the prior studies, which makes it difficult to draw conclusions about the efficacy of social disorganization to explain the variation in crime rates in rural communities and makes us wonder if these inconsistent findings are the result of the theoretical (i.e., model misspecification) and methodological (e.g., reliance on official crime data) limitations.

Interestingly enough, in their now classic article on community structure and crime that presented the first test of the full social disorganization model in the literature more than 20 years ago, Sampson and Groves (1989) complained of these same exact three limitations in the literature at the time. Their answer was to employ the British Crime Survey (BCS), which provided both victimization data (thereby addressing the reliance on official crime data to that point) and measures of local community organization based on information gathered from respondents (thereby gaining information about the mediating variables and allowing for a test of the full model). Faced with the same limitations with the rural crime literature, our answer (Kaylen \& Pridemore 2013b) was to do the same thing. That is, we drew on the BCS for data on social cohesion and crime victimization to present the first test of the full social disorganization model in the rural literature.

Using data from 8,630 respondents living in rural areas of 320 postcode sectors, we employed weighted least squares regression to estimate the effects of (1) the traditionally accepted exogenous sources of social disorganization - low socioeconomic status, ethnic heterogeneity, residential instability, and family disruption - on our intervening measures of community organization - density of local friendship networks, problematic teenage groups, and organizational participation - and (2) all these variables on property and violent victimization rates. This represents the first test of the full systemic social disorganization model in the rural literature.

Our results provide little support for the model. We did find evidence that the mediating variables representing community disorganization are associated with property and violent victimization. Yet while two of these three intervening indicators, density of local friendship networks and problematic teen groups, were associated with crime, these variables themselves were not at all well explained by the structural factors traditionally associated with the social disorganization model. Sampson and Groves $(1989$, p. 788$)$ argued that problematic teenage peer groups were "the most crucial mediating variable in the socialdisorganization model" and found four of their five structural antecedents (including urbanization, which we did not use because our focus was on rural communities) to be 
significantly associated with these groups in the expected direction. In a more recent study, Lowenkamp et al. (2003) used the entire BCS sample data (i.e., including urban areas) from the same year we used, and found the same four of five structural variables to be significantly associated with teenage peer groups. In our sample of rural areas, however, only one of the four (not five because we are not using population density because ours is a rural sample) structural variables, socioeconomic status, was associated with problematic teenage groups. In addition, only one of four structural factors, SES, was associated with density of local friendship ties, and ethnic heterogeneity and residential stability were significantly associated with friendship ties in directions opposite expectations. While these same two structural variables were also associated with organizational participation, the latter had no effect on either property or violent victimization. Finally, despite some significant associations, none of the models account for much variation in either the intervening variables or the crime rates. For the two intervening variables that ended up being associated with crime-local friendship ties and problematic teenage groups-the structural factors account for only 22 percent and 8 percent, respectively, of the variation. Furthermore, the final property and violent crime models have adjusted $\mathrm{R}^{2}$ values of only 14 and 12 percent, respectively.

Scholars have inferred from the results of these incomplete misspecified tests that the full systemic model operates as hypothesized, concluding that social disorganization is a robust explanation of the variation in rural crime rates, and thus that social disorganization operates in rural areas in essentially the same way as it does in urban areas and so is generalizable to rural areas. The findings from our first test of the full model, using the same data source and methods as the classic Sampson and Groves (1989) article, suggests otherwise.

Summary of Findings: A Thread of Consistency: As we described above, in spite of the general conclusion that the social disorganization model generalizes to rural areas, there are some inconsistent findings in the prior empirical literature. Similarly, the conclusions we drew from our initial study were very different from those of Osgood and Chambers.

Nevertheless, there is a strong thread of consistency in the findings of the studies we have undertaken thus far. Remember that in our Missouri sample using victimization data, the only social disorganization variable associated with rural crime rates was female-headed households. Similarly, when we used Osgood and Chambers' sample but substituted victimization data, we again found that the only social disorganization variable associated with crime rates was female-headed households. Finally, the analogous variable from the test of the full model, family disruption, was not associated with any of the mediating community organization variables, but it did retain its direct effects on crime rates and in fact (1) just as in our prior studies was the only structural antecedent associated with crime and (2) was more strongly associated with violent crime rates than the mediating measures of community organization. Thus, while our findings are inconsistent with prior conclusions drawn from the empirical literature on social disorganization and crime in rural areas, our findings have been internally consistent across our three studies in spite of very different samples (our initial Missouri sample, Osgood and Chambers' multi-state sample, and a rural sample from the UK) and measures of criminal victimization (hospital data from the United States and self- 
report victimization data from the British Crime Survey). What is also consistent in these studies, of course, is a lack of support for the social disorganization model in rural areas.

\section{Future Directions}

Although our three recent studies have addressed a number of methodological and theoretical limitations of past rural social disorganization research, numerous opportunities for research advancements in this area exist, addressing measurement, methodology, and theory.

Our finding that differences between the Osgood and Chambers (2000) paper and our original paper (Kaylen \& Pridemore 2011) are due to measurement of the dependent variable has critical implications beyond these two papers (Kaylen \& Pridemore 2013a). Specifically, it is implied that using these same measures of the dependent variable in other studies (both those that test social disorganization theory in rural areas and those that test other theoretical models) might also yield different results. To add to their blunt statements about county-level UCR data quoted above, Maltz and Targonski $(2002,313)$ also found that "smaller counties are more likely to have reporting deficiencies than larger counties," and even for homicide Wiersema, Loftin, \& McDowall $(2000,334)$ found that "homicide data sources are not interchangeable at the county level... [and at] smaller geographic scales the data source can make a difference in estimates of relationships between variables." Thus, crime and violence measurement is one of the most important areas of future work in the rural social disorganization literature generally and the rural crime literature specifically.

As discussed above, we suggest an alternative to arrest data for tests of social disorganization in rural areas is hospital violent victimization data. A manuscript we currently have under review uses the National Crime Victimization Survey to compare rural, suburban, and urban rates of victims of serious assaultive violence reporting to the police, presenting to the emergency room, both, and neither. Further research related to the validity and reliability of hospital data as an alternative source of violence data is crucial. Research should look at, among other things, victim, offender, and incident characteristics associated with victim decisions to report to the police and present to the hospital. That is, are these characteristics similar for rural, suburban, and urban victims? These questions can provide

guidance on whether or not comparisons can be made across community types when utilizing these data. Furthermore, spatial studies on the relationship between presenting to the emergency room and incident location could be useful.

In order to best test social disorganization theory in rural communities, we suggest the use of a rural-specific victimization survey. This type of survey could benefit from asking questions about both standard crimes and rural-focused crimes (e.g., livestock theft). Furthermore, questions about social disorganization could take on both a standard approach (similar to those questions in the British Crime Survey) and a rural-focused approach. For example, the definition of "neighbor" is likely different in rural and urban communities. Whereas the BCS asks about how many people someone considers to be their friends within a 
10 to 15 minute walk of their home, a rural victimization survey could ask about friends within the area the person considers to be their neighborhood.

A rural victimization survey could further be useful theoretically for testing whether there are rural-specific aspects of social disorganization. That is, the mediating variables in the social disorganization model may be similar in rural and urban areas but the structural antecedents may be different. As discussed above, Osgood and Chambers (2000) and others (Bouffard \& Muftić 2006; Lee, Maume, \& Ousey 2003) suggest the interaction of poverty and other structural factors might be different in rural and urban communities with regard to crime. It may be that other structural factors are also important in rural studies. As we suggest in one of our papers (Kaylen \& Pridemore 2013b), the spatial composition of rural communities may affect levels of social disorganization. For instance, rural small towns in which people live near each other may be more cohesive than a rural farming community. Furthermore, the nature of farms in the community may have an effect on levels of social cohesion: areas with family farms are likely to be exhibit more cohesion than areas with large factory farms. This approach to social disorganization theory in rural communities aligns with Weisheit, Falcone, and Wells's (2006) idea that social life in rural communities revolves around social institutions. Future research should explore not only the effects of the types of industry in rural communities, but also whether residents utilize internal social institutions (e.g., schools, churches, community centers) or travel outside the community for such institutions. Finally, with regard to the structural antecedents of social disorganization possibly operating different in rural and urban areas, Osgood and Chambers (2000) emphasize the consistency and strength of the family disruption measure (female-headed households) in rural studies. Future work should further investigate the interaction of this variable with other structural variables.

Moving along the social disorganization model, future work would benefit from looking more at the association between levels of social organization and crime in rural communities. Again, this type of work could be greatly aided by the development of a rural victimization survey. It may be that differences exist in the nature of social relations and crime in rural and urban communities, as suggested by Donnermeyer (2006). That is, some types of crime may be facilitated by community organization in rural areas. Instances of this phenomenon in rural areas include livestock theft (Barclay et al. 2004; Donnermeyer \& Barclay 2005), violence against women (DeKeseredy \& Schwartz 2009; DeKeseredy et al. 2006), and methamphetamine use (Roussell et al. 2009).

\section{Conclusion}

The relatively recent attention of scholars to rural crime, and specifically to testing social disorganization theory in rural areas, is an important step for the criminological community to extend our understanding of crime to all communities rather than just urban centers. However, this literature faces a number of limitations. These limitations, in fact, are the exact limitations Sampson and Groves (1989) addressed in their seminal article on social disorganization theory. To reiterate, these limitations include inability to test the full systemic 
social disorganization model, reliance on official crime data (which have known measurement error), and inconsistencies in the literature that tests the direct effects of the structural antecedents of social disorganization on crime. Although many are willing to accept that the theory generalizes to rural areas, these limitations are of serious concern. We (the authors of this paper) have begun to systematically address these limitations in a series of three articles, as described in detail above. The most consistent finding, thus far, is a lack of support for the generalizability of the theory, as it has been tested, to rural communities.

Whatever the reason or mechanism, it may be that social disorganization theory as an explanation for the distribution of violence rates does not generalize to rural areas. Based on our results and those of others, we are not ready to come to this conclusion. On the other hand, we do believe that many have drawn strong conclusions about the generalizability of social disorganization to rural areas based largely on the results of a single study, when in fact further research in required to answer the theoretical questions under scrutiny. 


\section{Endnotes}

1. Maltz and Targonski $(2002,2003)$ describe several measurement problems that threaten the validity of county-level UCR arrest data. Two of these include missing data and imputation of these missing data. Depending on the data source (i.e., local law enforcement agencies that usually do not impute their data, the FBI, or the National Archive of Criminal Justice Data), the values for any particular county will be different (Maltz \& Targonski 2002). A third problem with UCR arrest data is specific to counties with small populations, which is obviously important for those interested in rural crime. The details can be found in the sources cited here, but in short Lott and Whitley (2003) agreed with the Maltz and Targonski finding that "smaller counties are more likely to have reporting deficiencies than larger counties" (2002, 313). Further, Maltz and Targonski concluded that "at this point, county-level crime data cannot be used with any degree of confidence" $(2002,316)$, suggesting that "all studies that use aggregated UCR data-especially at the county levelshould be looked at carefully to determine the extent to which coverage gaps and imputations affect their findings" $(2002,317)$. Due to these conclusions, which came after the publication of the Osgood and Chambers' study, we used violent victimization data from hospitals as our measure of youth serious violent victimization. Hospitals collect data on patients who present to the emergency room. Patients are assigned external cause of injury codes (E-codes) based on the causes of their injuries, including assault (X85-Y09). These E-codes are based on the World Health Organization's International Classification of Diseases (ICD) codes and are uniform across hospitals (World Health Organization 2007). Research has shown these codes to be a reliable source of information about assault injuries treated in hospitals (LeMier, Cummings, and West 2001), and these type of data are commonly used in studies of violence (e.g., Fabio et al. 2004; Fabio et al. 2009; Gruenewald et al. 2006). 


\section{References}

Anselin, L. 1995. Local indicators of spatial association: LISA. Geographical Analysis 27, 93-115.

Barclay, E., Donnermeyer, J. F., \& Jobes, P. C. 2004. The dark side of Gemeinschaft: Criminality within rural communities. Crime Prevention and Community Safety: An International Journal 6, 7-22.

Barnett, C., \& Mencken, F. C. 2002. Social disorganization theory and the contextual nature of crime in nonmetropolitan counties. Rural Sociology 67, 372-393.

Bouffard, L. A., \& Muftić, L. R. 2006. The "rural mystique": Social disorganization and violence beyond urban communities. Western Criminology Review 7, 56-66.

DeKeseredy, W. S. \& Schwartz, M. D. 2009. Dangerous Exits: Escaping Abusive Relationships in Rural America. New Brunswick, NJ: Rutgers University Press.

DeKeseredy,W. S., Schwartz, M. D., Fagin, D., \& Hall, M. 2006. Separation/divorce sexual assault: The contribution of male support. Feminist Criminology 1, 1-23.

Donnermeyer, J. F. 2006. Rural crime: Roots and restoration. Paper presented at the International Conference on Rural Crime. 2006. Online. http://www.ruralfutures.une.edu.au/rurcrime/resources/proceedings/Donnermeyer.pdf

Donnermeyer, J. F. \& Barclay, E. 2005. The policing of farm crime. Police Practice and Research 6, 3-17.

ESRI. 2009. ArcMap 9.3.1. ESRI.

Fabio, A., Li, W., Strotmeyer, S., \& Branas, C. C. 2004. Racial segregation and county level intentional injury in Pennsylvania: Analysis of hospital discharge data for 1997-1999. Journal of Epidemiology and Community Health 58, 346-51.

Fabio, A., Sauber-Schatz, E. K., Barbour, K. E., \& Li, W. 2009. The association between county-level injury rates and racial segregation revisited: A multilevel analysis'. American Journal of Public Health 99, 748-53.

Freudenburg, W. R. 1986. The density of acquaintanceship: An overlooked variable in community research. American Journal of Sociology 92, 27-43.

Gruenewald, P. J., Freisthler, B., Remer, L., LaScala, E. A., \& Treno, A. 2006. Ecological models of alcohol outlets and violent assaults: Crime potentials and geospatial analysis. Addiction 101, 666-77. 
Kaylen, M. T. 2010. A Test of Three Methodological Explanations for Inconsistencies in Rural Social Disorganization and Youth Violence Research. MA thesis. Indiana University, Department of Criminal Justice.

Kaylen, M. T., \& Pridemore, W. A. 2011. A reassessment of the association between social disorganization and youth violence in rural areas. Social Science Quarterly 92, 9781001.

Kaylen, M. T., \& Pridemore, W. A. 2013a. The association between social disorganization and rural violence is sensitive to the measurement of the dependent variable. Criminal Justice Review 38.

Kaylen, M. T., \& Pridemore, W. A. 2013b. Social Disorganization and Crime in Rural Communities: The First Direct Test of the Systemic Model. Manuscript under review. Available from authors.

Lee, M. R., Maume, M. O., \& Ousey, G. C. 2003. Social isolation and lethal violence across the Metro/Nonmetro divide: The effects of socioeconomic disadvantage and poverty concentration on homicide. Rural Sociology 68, 107-131.

LeMier, M., Cummings, P., \& West, T. A. 2001. Accuracy of external cause of injury codes reported in Washington State hospital discharge records. Injury Prevention 7, 334-38.

Li, Y. 2011. Social Structure and Informal Social Control in Rural Communities. International Journal of Rural Criminology 1, 63-88.

Lott, J. R. Jr., \& Whitley, J. 2003. Measurement error in county-level UCR Data. Journal of Quantitative Criminology 19, 185-198.

Lowenkamp, C. T., Cullen, F. T., \& Pratt, T. C. 2003. Replicating Sampson and Groves's test of social disorganization theory: Revisiting a criminological classic. Journal of Research in Crime and Delinquency 40, 351-373.

Maltz, M. D., \& Targonski, J. 2002. A Note on the use of county-level UCR data. Journal of Quantitative Criminology 18, 297-318.

Maltz, M. D., \& Targonski, J. 2003. Measurement and other errors in county-level UCR data: A reply to Lott and Whitley. Journal of Quantitative Criminology 19, 199-206.

Moran, P. A. P. 1950. Notes on Continuous Stochastic Phenomena. Biometrika 37, 17-23.

Osgood, D. W. 2000. Poisson-Based Regression Analysis of Aggregate Crime Rates. Journal of Quantitative Criminology 16, 21-43.

Osgood, D. W., \& Chambers, J. M. 2000. Social disorganization outside the metropolis: An analysis of rural youth violence. Criminology 38, 81-115. 
Petee, T. A., \& Kowalski, G. S. 1993. Modeling rural violent crime rates: A test of social disorganization theory. Sociological Focus 26, 237-289.

Roussell, A., Holmes, M. D., \& Anderson-Sprecher, R. 2009. Community characteristics and methamphetamine use in a rural state: An analysis of preincarceration usage by prison inmates . Crime and Delinquency (OnlineFirst). http://cad.sagepub.com/content/early/2009/07/01/0011128709336939

Sampson, R. J. 1985. Neighborhood and crime: The structural determinants of personal victimization. Journal of Research in Crime and Delinquency 22, 7-40.

Sampson, R. J. \& Groves, B. 1989. Community structure and crime: Testing socialdisorganization theory. American Journal of Sociology 94, 774-802.

Weisheit, R. A., Falcone, D. N., \& Wells, L. E. 2006. Crime and Policing in Rural and Small-Town America. 3rd edn. Prospect Heights, IL: Waveland Press.

Weisheit, R. A., and Wells, L. E. 1996. Rural crime and justice: Implications for theory and research. Crime \& Delinquency 42, 379-397.

Weisheit, R. A., and Wells, L. E. 2005. Deadly Violence in the Heartland: Comparing Homicide Patterns in Nonmetropolitan and Metropolitan Counties. Homicide Studies 9, 55-80.

Wells, L. E., \& Weisheit, R. A. 2004. Patterns of rural and urban crimes: A county-level comparison. Criminal Justice Review, 29, 1-22.

Wiersema, B., Loftin, C., \& McDowall, D. 2000. A Comparison of supplementary homicide reports and National Vital Statistics System Homicide Estimates for U.S. Counties. Homicide Studies, 4, 317-340.

World Health Organization. 2007. International Classification of Diseases and Related Health Problems: 10th Revision. World Health Organization. http://www.who.int/classifications/apps/icd/icd10online 